\title{
Do Rigor Gartesiano Disciplinar à Indisciplinaridade Feyerabendiana
}

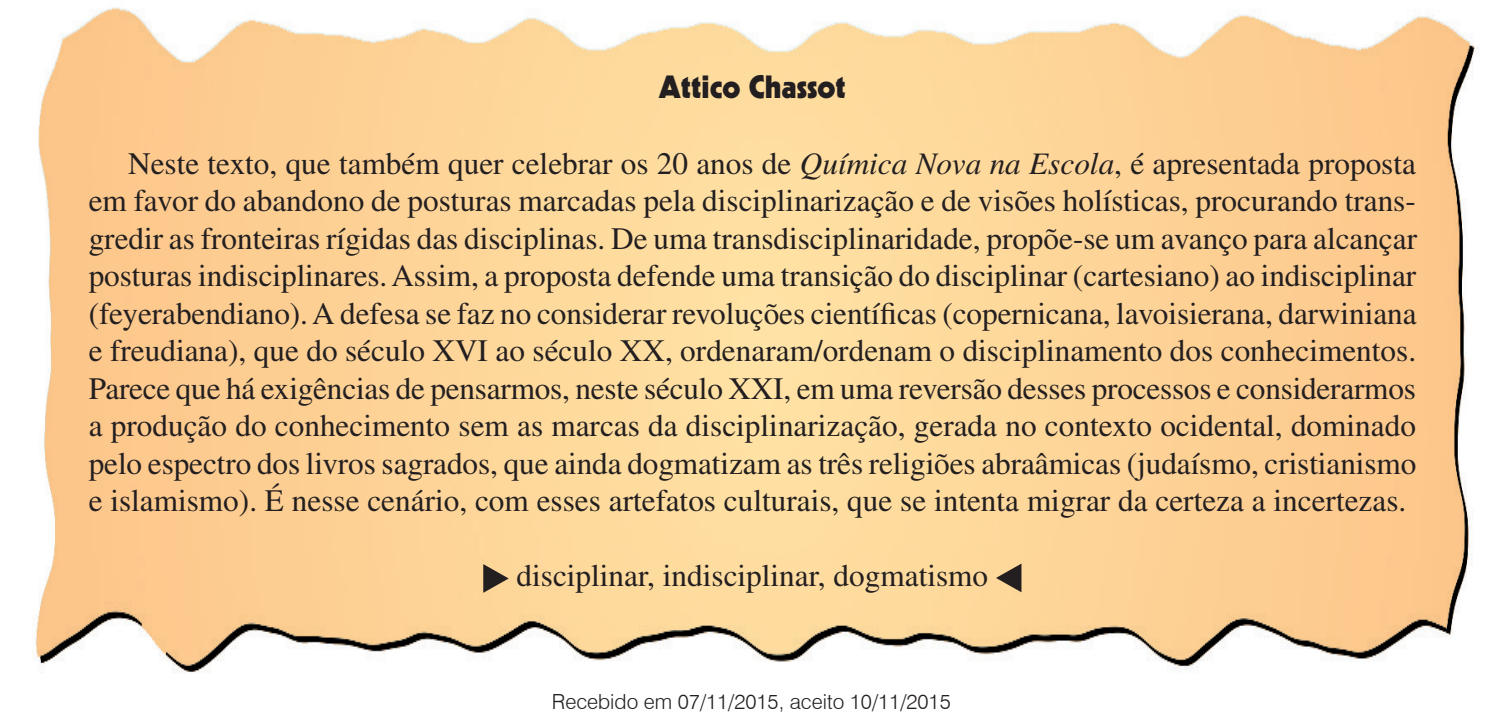

$\boldsymbol{Q}$ uímica Nova na Escola faz 20 anos. Esse é um evento muito significativo quando consideramos a periodicidade e/ou caducidade de revistas similares. Assim, é muito significativa a proposta de seus atuais editores em convidar aqueles que, há um tempo, envolveram-se na fundação e produção da revista para colaborarem com evocações, fazendo memórias da trajetória percorrida pelo nosso periódico. Recebemos sugestões de temas.

Não há como fugir de um texto intimista, pois olhar os 20 anos da QNEsc é olhar também nossas histórias pessoais de pessoas fazendo educação. Não vou falar da história da revista. Ensaio falar do cenário da educação química que a revista viveu e especialmente transformou nessas duas décadas.

Parece que seja trivial afirmar que a educação química, pelo menos no Brasil, não é mais a mesma e isso se deve também à QNEsc. Se a afirmação anterior é tida como fácil, agora enuncio outra, pelo menos audaciosa. Mesmo que a revista aqui celebrada ostente química em seu nome e mesmo que há mais de 30 anos façamos eventos de educação química, ouso afirmar que, passados um quarto de século da publicação dos primeiros livros de educação química no Brasil, somos menos educadores químicos. Somos mais professores de ciências do que professores de química. Fizemos alfabetização científica, formamos mestres e doutores em ensino de ciências. Radicalizo mais: quase perde o sentido falarmos em educação química.

Essa afirmação é feita na mirada de pelo menos quatro revoluções científicas (copernicana, lavoisierana, darwiniana e freudiana) que, desde o século XVI ao século XX, ordenaram/ ordenam o disciplinamento dos conhecimentos. Parece que há exigências de pensarmos neste século XXI, em uma reversão desses processos, e considerarmos a produção do conhecimento sem as marcas da disciplinarização, gerada no contexto ocidental dominado pelo espectro dos livros sagrados que ainda dogmatizam as três religiões abraâmicas (judaísmo, cristianismo e islamismo). É nesse cenário, ou melhor, é com esses artefatos culturais que ocorreram as revoluções científicas. 
Esse contexto tem determinado um dogmatismo disciplinar à chamada ciência moderna que, neste texto, se quer discutir. Um quadro-síntese poderia ser assim desenhado.

\section{Algumas significativas rupturas paradigmáticas...}

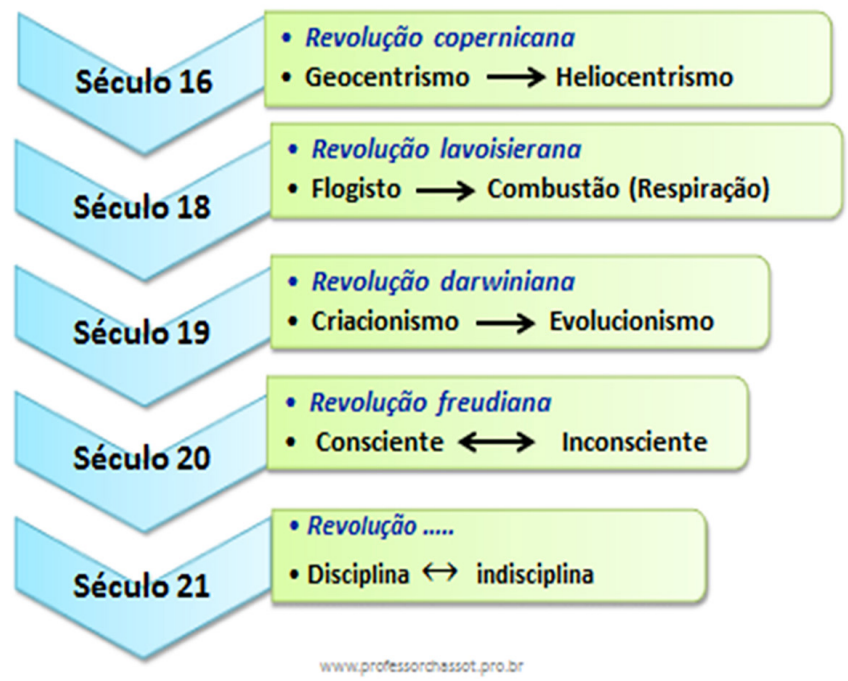

Houvesse ainda censura às publicações, um censor mais rigoroso não daria um imprimatur est a este texto nesta revista. No entanto, contrariamente a que possa parecer, não alço aqui a bandeira da iconoclastia, pois mesmo que proponha a indisciplinaridade, aceito a existência de disciplinas. Esta é, paradoxalmente, a proposta que intento ampliar nesta edição jubilar de QNEsc. Ela não é inédita (Chassot, 2008b). Na esteira da busca de outro ensino médio, também já trazia essa discussão (Chassot, 2014).

Aqui e agora, reafirmo algo, não sem certo constrangimento, pelas continuadas limitações que as considerações já trazidas em outros textos e, especialmente, em dezenas de palestras que trazem como título: das disciplinas à indisciplina. As análises que apresento prosseguem sendo um recorte apenas de leituras do mundo ocidental. Nesse recorte, a partir do dito nascimento da ciência moderna no século XVI, o conhecimento se faz cada vez mais disciplinar. Esse alerta é preciso, pois nós, com nosso autocentramento, continuamos, por diferentes razões, sendo umbigocêntricos, marcados talvez pelo nosso forte DNA grego. É preciso recordar que, para nossos ancestrais helênicos, quem não falasse grego era bárbaro.

Mais uma vez, interrogantes aportam fortes: quem é o oriente? Quem é o ocidente? Parece pouco crível o quanto este ainda parece ser sinônimo da cristandade (não na acepção dicionarizada de maneira corrente: conjunto dos cristãos, mas num recorte geográfico, isto é: ocidente é a Europa e as terras por ela colonizadas. Assim, parece ficar estabelecido o ocidente como uma circunscrição definida quanto à territorialidade e, por conseguinte, fica esclarecido qual o entendimento de civilização europeia.

É usual, ao nos envolvermos com a história da ciência e de uma maneira mais ampla com a história da construção do conhecimento, centrarmo-nos quase exclusivamente no mundo ocidental e o fazermos sob a ótica eurocêntrica, e esta alimentada por nossos olhares brancos, masculinos, cristãos... Pouco sabemos de como ocorreu a construção do conhecimento em diferentes culturas no oriente. Ainda hoje, por exemplo, filmes ambientados na China ou na Índia, apenas para referir aos dois países orientais mais populosos, trazem-nos surpresas. Mesmo nos dias atuais, conhecemos muito pouco, por exemplo, da educação na China, apenas para referir a um país onde vivem cerca de um quinto dos humanos.

Aliás, poderia retratar o ápice de nossa presunção de falar dos outros, citando Edward W. Said (2007), quando o reconhecido pensador palestino mostra que o oriente, mais que uma concepção geográfica, engloba tudo que não sejam as civilizações europeias ${ }^{1}$. E esse oriente é uma invenção do ocidente.

É preciso considerar que esse ocidente, balizado inicialmente sob o poderoso Império Romano que, mesmo quando sai de cena quase esfrangalhado no século $\mathrm{V}$, deixa um legado portentoso que garantiria hegemonia: o latim. Originário da região itálica do Lácio, o latim é uma das marcas mais imponente do ocidente. Como língua oficial do Império Romano, ele é imposto aos colonizados. Talvez, o melhor exemplo disso é o latim substituir o grego quando Roma coloniza a Grécia, dois séculos antes da Era Cristã, quando os romanos latinizam a filosofia grega e os deuses (Zeus passa ser Júpiter e assim todo o panteão de divindades gregas são convertidas a divindades romanas). Igualmente acontece no norte da África: em Alexandria, a resistência de Hipátia é um exemplo. As nascentes do direito, da filosofia, da ciência, da literatura e, especialmente, da religião são em latim. Mesmo com o esfacelamento do latim em mais de uma dezena de línguas românicas (como, por exemplo, o português), este segue como a língua oficial (e o garantidor da catolicidade ${ }^{2}$ ) da igreja romana até o Concílio Vaticano II (1962-1965)3. Ainda na segunda metade do século XX, o ensino da filosofia em escolas seminarísticas era feito em latim. Até o Concílio Vaticano, toda liturgia da igreja católica romana, para todos os fiéis, era em latim.

Assim, reconheço o quanto eu fui reducionista ou mesmo simplista em A ciência através dos tempos (Chassot, 1994), quando me refiro à revolução copernicana ratificada pela revolução galilaica e encimo o capítulo com um título no mínimo tendencioso: Século 16: nasce a ciência moder$n a$, numa leitura que desconhece o que se fez no mundo não europeu. Reabilito-me, um pouco, em outros textos e especialmente quando, nesse mesmo livro, a partir de sua edição de 2004, apresento um novo capítulo: Uma história da ciência latino-americana determina outro marco zero. Neste, acena-se para possíveis leituras do desenvolvimento em épocas pré-colombianas do que chamamos hoje de arquitetura, engenharia, agronomia, astronomia, hidrologia, matemática, medicina, isto é, a existência de atividades científicas relevantes. Nessa dimensão, indicam-se possibilidades de outras duas leituras: i) a influência da relação da ciência e tecnologia no desenvolvimento de altas culturas na América 
pré-colombiana; e ii) a (re)valorização desses conhecimentos e técnicas, não apenas para fazer um resgate histórico, mas numa tentativa de mostrar o quanto a recuperação dos conhecimentos (quase) perdidos podem ser importantes para a população latino-americana que vive em situação de pobreza.

Talvez, quando soubermos melhor explicar por que no oriente não houve (ou não precisou ter) revolução científica, tenhamos mais convincentes explicações de nossa acerbada visão disciplinar. Isso será facilitado também por leituras aprendidas no budismo e ainda em outras filosofias orientais ${ }^{4}$. A estas, provavelmente consigamos acrescentar também as marcas do islamismo em nossa formação; e nas ciências, o quanto essa vertente é forte. Outra dimensão nos recortes que fazem minhas análises serem ainda empobrecida é a ausência das muito importantes contribuições da matriz africana. Acerca da matriz indígena, como referi no parágrafo anterior, está se buscando contribuições como, por exemplo, Chassot e Camargo (2015).

É salutar nos desafiarmos para responder a esta pergunta: No oriente, não ocorreu revolução científica por influência de filosofias orientais, pois a maneira de estar no mundo não teve exigências de uma ciência marcada por certezas? ou A ocorrência de revoluções científicas no ocidente pode ser creditada a maneira cristã de estar no mundo?. Talvez, uma síntese que poderia ser tema de uma significativa tese doutoral: é a presença de livros sagrados (Torá, Bíblia ou Corão), resguardada por uma ortodoxia religiosa, que fez um fértil substrato para revoluções científicas?. Afinal, não é, por exemplo, a matemática do livro que tem mais valor frente à etnomatemática.

Como argumento à tese: "é a presença de um livro sagrado (Torá, Bíblia ou Corão) para cada uma das três religiões abraâmicas, resguardado por uma ortodoxia religiosa, que fez substrato para revoluções científicas", poderíamos recordar que as quatro maiores revoluções científicas tiveram suas certidões de nascimento exaradas por livros que não apenas abalaram o mundo, mas receberam aceitação e garantiram uma disciplinarização marcada por uma ortodoxia como já anunciei quase na abertura deste texto. Mesmo que a proposta aqui seja olhar como nos fizemos sujeitos disciplinares, parece que a tese antes enunciada devesse permear algumas das considerações trazidas neste texto.

Olho um bordado. Encantam-me as tramas. Parece uma pintura. Depois, observo o avesso. Não parece crível que aquele emaranhado de fios, que mais parece uma maçaroca, tenha produzido aquele bordado. Portanto, aqui e agora, parece importante que vejamos um pouco do avesso de uma longa e também cruenta trajetória. Algumas considerações acerca de cinco rupturas que estão no diagrama anterior evidenciam uma proposta contrária àquela que se quer defender. Eis um aparente paradoxo: evidenciaremos como, no correr de cinco séculos, construímos a disciplinarização para sonharmos quase em um retorno utópico a posturas do século XVI no que se refere a uma visão mais holística do conhecimento. A proposta parece um tanto fora de propósito. Sabe a retrocesso. Assumo.

Recordando que holismo (do grego holos, que significa inteiro ou todo) é a ideia de que as propriedades de um sistema, quer se trate de seres humanos ou outros organismos, não podem ser explicadas apenas pela soma dos seus componentes. É o sistema como um todo que determina como se comportam as partes e cada uma individualmente não reflete necessariamente o todo. O princípio geral do holismo pode ser resumido por Aristóteles, na sua Metafísica, quando afirma: o todo é maior do que a simples soma das suas partes. Mesmo que saiba tudo acerca de uma disciplina, isso não me autoriza (ou garante) conhecer a outra. Essa é uma das teses a propostas indisciplinares.

Se no diagrama antes destacado temos uma (quase) síntese da história da construção (disciplinar) do conhecimento no ocidente, temos também as marcas de um embate que a cada momento está presente em nosso cotidiano: especialista versus generalista. É evidente que mesmo aceitando que conhecimento cresce (ultrapassa fronteira) nas ações dos especialistas, aqui privilegiaremos a trazida de concepções generalistas. Afinal, na escola que, com a QNEsc, sonhamos ajudar a transformar, devemos formar generalistas.

No Sete escritos sobre educação e ciências (Chassot, 2008 p. 93-140), há um capitulo em que se fez uma leitura da história da construção do conhecimento, destacando as três primeiras (na ordem de citação no diagrama) das mais significativas revoluções paradigmáticas da ciência moderna. Naquele texto, tenta-se mostrar como essas revoluções determinaram/ determinam a disciplinarização. E mais: ao olharmos a gênese desse fenômeno, procurou-se encontrar situações que determinem o afloramento de propostas transdisciplinares. Em oposição às consequências dessa disciplinarização, tem-se buscado apoio de propostas que permitam a leitura mais holística antes referida.

Aqui é significativa uma comparação das três primeiras revoluções com as duas últimas. Recordemos Tomas S. Kuhn (1922-1996). Ele, em A estrutura das revoluções científicas (Kuhn, 1987), considera uma ciência madura quando uma sucessão de tradições, cada uma tendo a sua própria teoria e os seus métodos de pesquisa, serve de paradigma para a comunidade científica durante certo tempo antes de ser abandonada.

Toda revolução científica se traduz numa mudança de 
paradigma. Vejamos as três primeiras: com o advento do heliocentrismo, deixa de existir o geocentrismo; a explicação da combustão alija o flogisto das explicações do por que algo queima; e o evolucionismo supera (ou sonhadoramente deveria superar! E aqui, é preciso já anunciar agora: temos a mais dramática das cinco revoluções) o dogma do criacionismo. Todavia, na medicina, na psiquiatria, na psicanálise, na psicologia, de maneira mais usual, o advento de um novo paradigma não exclui as propostas teóricas da geração anterior, mas as abarca, dando nova significação. Na quarta revolução paradigmática, introdução por Freud do inconsciente não faz deixar de existir o consciente. A homeopatia pode coexistir com a alopatia. No diagrama, isso está representado pelas setas simples nas três primeiras revoluções, enquanto que na quarta temos a dupla seta. Isso que se referiu para a revolução freudiana - a coexistência do antes com o depois - quer ter a mesma leitura para a quinta revolução que está no diagrama. Essa última afirmação pode trazer conforto a alguns: as disciplinas subsistirão após a quinta revolução.

O conceito de revolução científica, tomado da ciência política por Kuhn (1987, p. 126), serve para “aqueles episódios de desenvolvimento não cumulativo, nos quais um paradigma mais antigo é total ou parcialmente substituído por um novo, incompatível com o anterior", ou seja, é uma reconstrução da área que altera conceitos, leis, teorias, métodos e aplicações.

Aqui e agora, este não é um texto de história da ciência, mas é sobre história da ciência, mostrando o quanto ela pode catalisar ações em sala de aula que sejam contrárias à ossificação determinadas pela disciplinarização. Assim, aqui se examina - e não se descreve - as revoluções copernicana, lavoisierana e darwiniana e, nestas, procura-se ver o quanto e como foi determinado o fortalecimento das disciplinas, particularmente a física, a química e a biologia. Então, quase numa contrarrevolução, chega-se à transdisciplinaridade e, a seguir, num crescendo, à indisciplinaridade - talvez uma culminância dentre diferentes maneiras de fazermos educação com as ciências ou, se quiserem, educação nas ciências e que se cogita (ou melhor, se sonha com) a migração das disciplinas à indisciplina que também se traduz no abandono de nossas certezas, buscando conviver cada vez mais com a incerteza.

Aqui e agora, a proposta é nos aliarmos àqueles que, há mais tempo, buscam alternativas onde até a indisciplina possa ser uma das metodologias para uma mais eficiente alfabetização científica de alunos. Propostas como essas já têm estado, há pelo menos uma década, presentes em muito de minhas falas e escritos, quando se procura enveredar por um crescend $^{5}$ : disciplinar $<$ pluridisciplinar $<$ multidisciplinar $<$ metadisciplinar $<$ interdisciplinar $<$ transdisciplinar $<$ indisciplinar. Não detalho esses distintos níveis, pois especialmente os primeiros têm sido objetos de extensos estudos.

Talvez valesse tomar como ponto de partida as discussões acerca da indisciplinaridade que, por ser o ápice dos diferentes níveis antes referidos, ainda não tem merecido muitos estudos e mesmo adesões. No entanto, para mais adequadamente fazê-lo, é oportuno vermos o nível que lhe é extremo, ou melhor, talvez aquele quase oposto: disciplinar ou um sinônimo que trânsito corrente: cartesiano.

Quando Descartes - no seu Discurso do Método de 1637 (1993) - coloca a análise como oposição à síntese, passa-se a exigir que uma etapa inicial para a construção do conhecimento seja a fragmentação deste, ou seja, reduzir o todo em frações representadas por seus componentes elementares. Isso passa a determinar fracionamentos cada vez maiores e mais específicos nas áreas do conhecimento. É bem verdade que há quase quatro séculos, quando Descarte propôs essa racionalização fragmentadora, não havia como prever tão extensa especialização daquilo que se chama(va) a ciência.

Assim somos cartesianos (sem o sentido pejorativo antes referido) quando tomamos uma parte da matéria e refinamos nossa ciência - aqui entendida como um construto humano para facilitar a leitura do mundo natural - sobre esta e colocamos nela nossas lentes para olharmos como ocorrem as transformações da matéria e dizemos nessa situação que estamos estudando química, deixando de nos interessar então, por exemplo, sobre as transformações físicas como modificações de estados ou suas variáveis. Se afinarmos mais nossas observações e dissermos que vamos observar aquelas transformações da matéria que são resultado de processos biológicos (assim não consideramos objeto de nossos estudos, por exemplo, a reação de combustão de uma folha de papel ou a formação de um sal inorgânico por uma reação de dupla troca), podemos falar na disciplina de bioquímica ou, então, se passamos a estudar somente as transformações que ocorrem na matéria em consequência das fermentações, então a disciplina objeto de nossos estudos é a bioquímica de fermentações.

Agora, tentemos ir ao extremo oposto do crescendo antes desenhado: o indisciplinar. Del Percio (2006) traz um desenho de uma situação que não é nada exótica em nossas ações que merece ser trazida aqui. As agências de fomento - o nome não poderia ser mais poético - tendem a contratar especialistas cada vez mais especializados para resolver segmentariamente um problema. A maior parte de análises, diagnósticos e propostas para dar respostas a uma demanda só tem uma característica comum: entender o problema com seus óculos específicos.

Nosso fazer educação não se consubstancia numa ilha programada por nossa fantasia. Há múltiplas realidades a nos alertar sobre a impossibilidade da existência de um mundo ideal. Vejamos uma situação concreta. Há um problema a resolver. Peritos de cada uma das áreas propõem soluções no terreno das outras. Vejamos múltiplas tentativas de solução de um mesmo problema como mostra:

1 - o educador considera que é impossível oferecer uma educação de qualidade a meninos cujos pais não têm trabalho e moradia adequada e sofrem de carências alimentares, portanto, propõe começar a resolver a questão do emprego, da moradia e da saúde.

2 - o experto em empregos sustenta que precisa começar 
atendendo às questões educativas, pois os novos modelos laborais requerem uma formação e capacitação tal que sem educação não pode haver emprego de qualidade; ainda afirma que se requer boas condições sanitárias da população para que se possa trabalhar adequadamente.

3 - o perito em segurança afirma que é preciso começar por educação, emprego e erradicação da pobreza, pois está comprovado estatisticamente - e isso é decisivo - que quanto maior o nível educativo, menor é o uso da violência e que quanto maior o nível de equidade social, menor a taxa de violência em geral.

4 - o perito em questões ambientais remete o início de suas ações à segurança, à educação, à saúde, ao emprego.

5 - o experto em saúde afirma que não há sistema de saúde sustentável sem pleno emprego (pois o sistema público não pode atender satisfatoriamente a toda a população), sem educação suficiente (base da prevenção) e sem condições ambientais e educacionais adequadas.

6 - o perito em habitações afirma que, sem emprego e sem educação, toda a política de moradias não passa de mero assistencialismo.

Como nenhum dos problemas centrais da vida é possível ser abordado sem múltiplas conexões com outros problemas vitais, resulta que parece impossível solucionarmos aquele problema no qual temos expertise. É preciso pensar, abandonando as nossas especializações, transgredindo as fronteiras de nossas disciplinas ou com uma postura que se assemelha a Feyerabend (2007, p. 71) que ensina: "Qualquer ideia, embora antiga e absurda, é capaz de aperfeiçoar nosso conhecimento. [...] o conhecimento de hoje pode, amanhã, passar a ser visto como conto de fadas; essa é a via pelo qual o mito mais ridículo pode vir a transformar-se na mais sólida peça da ciência". É em ações que tragam a marca daquilo que Del Percio (2006, p. 20) propõe como "a indisciplina como a metodologia mais adequada para abordar a análise das principais tendências sociais". Talvez a reunião dos seis peritos para juntos buscarem a solução do problema fosse a melhor alternativa.

Transmuto a proposta da área da sociologia, em que o autor desenvolve sua tese para o nosso fazer educação, até porque ninguém questionaria o quanto nos envolvemos em nossas ações de fazer alfabetização científica ou educação nas ciências como sendo uma ciência social. Assim, adiro às reflexões do autor nos três sentidos em que é proposto o termo indisciplina, e numa etapa mais audaciosa - mas, mais realista -, assumiremos uma escola indisciplinar. Nesta, o prefixo in tem pelo menos três ações:

a) o prefixo in no sentido de incluir a partir da própria disciplina, meter-se dentro de outras disciplinas. São as ações que vamos fazer para colocar nossas especificidades em outras disciplinas. Ações como aquelas traduzidas por impor-se, intrometer-se, incestar, invadir...

b) seguindo o mesmo sentido do prefixo in, trata-se de incorporar elementos, métodos e conhecimento de outras disciplinas. Aqui parece mais evidente o quanto temos buscar nas outras disciplinas, não nos bastando o mundo pequeno ou específico de nossa disciplina. Atividades como as que temos em verbos como inalar, ingerir...

c) o prefixo in como negação, trata de negar a disciplina no sentido etimológico do termo. Aqui a proposta parece ser mais radical ou inovadora: trata-se de rebelar-nos à coerção feita pelas disciplinas que, como um látego, vergastam-nos a submissão. Ações como as expressas por inverter, intolerar, inabitar...

Talvez essa última acepção do indisciplinar seja a mais radical: negar-se a existências das disciplinas mereça mais destaque. Nesse contexto, é importante retornarmos e revisitar termos como disciplina ou disciplina escolar. Disciplina na acepção que usamos é muito recente. Até o final do século XIX, essa expressão queria significar, segundo Chervel (1990, p. 178), a vigilância dos estabelecimentos de ensino ou repressão das condutas prejudiciais à sua boa ordem e aquela parte da educação que contribui para isso. Recordo que, quando fiz o curso ginasial, no final dos anos 1950, tínhamos semanalmente uma nota em comportamento, obtida em função da disciplina, num sentido atitudinal. As notas tinham um máximo de $10+5$, onde a primeira era para o conteúdo e a segunda para a disciplina ou a ordem. Essa ordem envolvia desde a caligrafia, limpeza no material escolar, corretos detalhes de cada peça do uniforme, pontualidade ou até escrever VJMJ (viva Jesus, Maria, José) no alto da margem esquerda da folha cada vez que se iniciava a escrita em uma nova página. Desses mesmos tempos, sempre evoco as placas que os irmãos maristas, ordem religiosa, então mantenedora do estabelecimento, colocavam em toda a parte, inclusive nos banheiros: "Deus me vê!". Mesmo que novos tempos a retiraram, eu ainda as vejo lá. Essa mesma advertência, marcada por exigente admoestação, foi ressuscitada em tempos pós-modernos pela cada vez mais numerosa presença das placas "Sorria, você está sendo filmado!". O aviso é mentiroso, pois o correto deveria ser: "Te cuida cara... nós estamos te olhando!".

Essa acepção para disciplina não está distante de disciplinas significando correias com que membros de certas ordens religiosas e devotos se açoitam por penitência ou castigo. É a esse disciplinar ou cartesiano que (pr)opomos o indisciplinar ou feyerabendiano.

\section{Como (quase) conclusão}

Quando celebramos os 20 anos de Química Nova na Escola e olhamos as ações da revista, exigimo-nos algumas perguntas: Quanto caminhamos nessa tentativa de migrar do disciplinar ao indisciplinar? Talvez nos escudemos, em busca de uma absolvição, por sermos lerdos nesse caminhar, em David Hume (1711-1776), filósofo e historiador escocês: "Se acreditamos que fogo esquenta e a água refresca, é somente porque nos causa imensa angústia pensar diferente!".

Não é fácil mudar. Nesses 20 anos, ensaiamos mudanças. Há sessões que facilitam isso, Relatos de sala de aula e $O$ aluno em foco. Há ainda seções em cuja proposta editorial se afirma que "deve-se explicitar contribuições para o ensino da 
química". Em quase todas as sessões, parece que centramos mais na química do que em uma visão mais ampla de ciências, e mais: essa ciência inserta no cotidiano de alunos. No entanto, não estamos parados. Talvez professemos demais o saber primevo que ensina que devagar se vai ao longe. Estamos recém-atingindo nossa maioridade e, para todos discentes e docentes envolvidos no binômio escrita $\leftrightarrows$ leitura, catalisado por Química Nova na Escola, é tempo de aprender.

Assim, parece que vale experimentar ser indisciplinado.

\section{Notas}

1 Tive dúvidas se escrevia civilizações europeias ou civilização europeia. Talvez, o mais correto, mesmo com a diversidade cultural étnica, expressarmo-nos no singular, pois uma das marcas da civilização europeia parece ter sido a busca de sua catolicidade, aqui usada uma vez mais na acepção de universal. Essa universalidade se esboroa com a transformação do latim em muitas línguas e é ratificada no século XVI com o fracionamento da igreja católica romana em decorrências do surgimento de igrejas reformadas. Assim, tenho justificativa, para adiante, referir-me à civilização europeia.

2 Católica, na acepção de universal.

3 Autorizo-me a uma digressão pessoal: antes de ser alfabetizado, eu sabia responder às orações da missa em latim, evidentemente sem entender o que eu (e muitas vezes

\section{Referências}

CHASSOT, A.I. A ciência através dos tempos. 2. ed. São Paulo: Moderna, 2008. Cortez, $2008^{\mathrm{a}}$

Sete escritos sobre educação e ciências. São Paulo:

. Da química às ciências: um caminho ao avesso. In: ROSA, M.I.P.; ROSSI, A.V. (Orgs.). Educação Química: memórias, políticas e tendências. Campinas: Línea, 2008b. p. 217-234.

Saberes primevos catalisando a indisciplinariedade. In: AZEVEDO, J.C.; REIS, J.T. (Orgs.). O ensino médio e os desafios da experiência: movimentos da prática. São Paulo: Santillana e Moderna, 2014. p. 115-133.

CHASSOT, A.I.; CAMARGO, C.G. A interculturalidade e as intempéries de chronos e kairós: sobre tempos indígenas e não indígenas na universidade. Revista Pedagógica, Chapecó, v. 17, n. 34, p. 59-74, jan./abr. 2015. o celebrante) papagueava(mos). Fui ensinado por minha mãe, muito religiosa, mas que não sabia os significados do que ensinava.

4 No segundo semestre de 2015, publiquei diferentes textos, fiz palestras e organizei seminários na graduação e na pós-graduação acerca da LAUDATO SI': Sobre o cuidado da casa comum, oportuna encíclica do Papa Francisco (2015) amealhando comentários de diferentes perspectivas. Entre estes, destaco o quanto a encíclica se caracteriza por ser “indisciplinar, pois permeia e é permeada em várias áreas do conhecimento. Ciência (não sei de alguma disciplina que não tenha sido referida com adequação), tecnologia (trazida com detalhes e com brilhante atualidade) e religião (a matriz judaico-cristã aflora de maneira permanente, ignorando o orientalismo) fazem uma tessitura bastante harmoniosa". Isto é, mesmo um documento que deve ter tido uma assessoria de uma plêiade de especialistas, ignora o pensamento oriental (mestrechassot.blogspot.com de 9 de julho e 05 de agosto de 2015).

5 Uso a palavra crescendo na acepção da musicologia que, segundo o Priberam, significa aumento gradual da intensidade sonora.

Attico Inácio Chassot (achassot@ gmail.com), licenciado em Química, doutor em Ciências Humanas, é professor do mestrado profissional de Reabilitação e Inclusão do Centro Universitário Metodista IPA. Porto Alegre, RS - BR.

CHERVEL, A. História das disciplinas escolares: reflexões sobre um campo de pesquisa. Teoria \& Educação, v. 2, p. 177229, 1990.

DEL PERCIO, E.M. La condición social: consumo, poder y representación en el capitalismo tardío. Buenos Aires: Altamira, 2006.

DESCARTES, R. Discurso do método. Trad. J. Guinsburg e Bento Prado Júnior. São Paulo: Abril Cultural, 1993. Coleção Os Pensadores.

FEYERABEND, Paul. Contra o método. São Paulo: Ed. UNESP, 2007.

KUHN, T. A estrutura das revoluções científicas. São Paulo: Perspectiva, 1987.

SAID, E.W. Orientalismo - o oriente como invenção do ocidente. Trad. Rosaura Eichenberg. São Paulo: Companhia de Bolso, 2007.

Abstract: From cartesian disciplinary rigor to feyerabendian indisciplinarity. In this text, which also wants to celebrate the 20th anniversary of Quimica Nova na Escola, it is presented a proposal in favor of abandoning positions marked by disciplinization and holistic views, looking for transgressing the rigid boundaries of disciplines. From transdisciplinarity it is stated a step forward to achieve indisciplinarity postures. So, the proposal advocates a transition from the disciplinar (Cartesian) to the indisciplinar (Feyerabendian).The defense is done with considering scientific revolutions (Copernican, Lavoisierian, Darwinian and Freudian) that, from the 16th century to the 20th century, ordered / order the disciplining of knowledges. It seems that, in this 21 st century, it is required to think in a reversal of these processes and consider the production of knowledge without the marks of the disciplinirization generated in the Western context, dominated by the specter of the sacred books, which still dogmatize the three Abrahamic religions (Judaism, Christianity and Islam).It is in this scenario, with these cultural mindfacts, that it is intended to migrate from certainty to uncertainties.

Keywords: disciplinary, indisciplinary, dogmatism. 